\title{
THE EFFECT OF CLIMATE CHANGE ON HABITAT SUITABILITY AND A DISTRIBUTION MODEL OF THE IRANIAN FAT-TAILED GECKO, EUBLEPHARIS ANGRAMAINYU ANDERSON AND LEVITON, 1966 (SAURIA: EUBLEPHARIDAE) SINCE THE LAST INTERGLACIAL TO 2050
}

\author{
Rasoul Karamiani*, Nasrullah Rastegar-Pouyani \\ Department of Biology, Faculty of Science, Razi University, Kermanshah, Iran \\ *Corresponding author. Email: rasoul.karamiani@gmail.com
}

\author{
Article history \\ Received: 7 October 2020 ; \\ accepted: 16 March 2021

\section{Keywords:} \\ Leopard gecko; climate \\ condition; suitable habitat; \\ Last interglacial; mid- \\ Holocene, future
}

\begin{abstract}
Surveying the role of climate changes on the species distributions in the past, present and future, and correlating these with changes in distribution ranges have attracted considerable research interest. The leopard geckos of the genus Eublepharis Gray, 1827 (family Eublepharidae), as a vicariate group, comprises six valid species distributed from Turkey through the Iranian Plateau to India, of which E. angramainyu, E. macularius and E. turcmenicus occur in Iran. In this study, we modelled the potential distribution areas for E. angramainyu and determined the suitable habitats in the past (the last interglacial [LIG] and mid-Holocene [MH]), present (1950-2000), and also predicted four scenarios in the future (2050) by using the maximum entropy approach (MaxEnt). The obtained models indicated very good values of the area under curve (AUC): $L I G=0.996 \pm$ $0.003, \mathrm{MH}=0.996 \pm 0.004$, contemporary period $=0.995 \pm 0.004$, and the future $=0.997 \pm 0.002$. Precipitation of the coldest quarter and precipitation of the warmest quarter were the most important factors shaping the distribution of E. angramainyu. As it seems, climatic changes have been responsible for a southward shift in distribution and suitable habitats of E. angramainyu from the LIG ( 150,000-120,000 years ago) to the future. The representative concentration pathway (RCP) 2.6 scenario model of the future predicted a much more restricted distribution and less suitable habitats due to radiation of the forcing level which reaches a value of around $3.1 \mathrm{~W} / \mathrm{m}^{2}$ by mid-century and returns to $2.6 \mathrm{~W} / \mathrm{m}^{2}$ by 2100 .
\end{abstract}

\section{INTRODUCTION}

Global climate change has considerably affected biodiversity, with changes in ecomorphological traits (e.g. shape of limbs), physiological performance (speed and strength), life-history and species distribution ranges (Walther et al. 2002; Hellmann et al. 2008; Visser 2008; López-Alcaide and Macip-Ríos 2011). The Pleistocene glaciations were separated by interglacial periods in the Northern Hemisphere (Ray 1992; Sillero and Carretero 2013). The climate of the last interglacial period (LIG: $150,000-120,000$ years ago) was relatively warm or warmer than the present (Kukla et al. 2002; Pickarski 2014). The climate of the mid-Holocene had relatively increased in rainfall along with wetter condition than in the contemporary period in southern and southwest Asia to northern Africa that resulted in both African and Asian monsoons (Texier et al. 2000; Wanner et al. 2008; Jones et al. 2011).

Analysis of species distribution models (SDMs) in the past (last interglacial and mid-Holocene periods) to the present and their changes can help in conservation strategic planning (Karamiani et al. 2018). SDMs predict potential habitat suitability based on evaluating the most important environmental variables for species across a distribution range (Gogol-Prokurat 2011). In other words, SDMs can be used to research the effect of climate changes on the distribution range of species (Thomas et al. 2004).

The genus Eublepharis (family Eublepharidae) encompasses six nocturnal lizard species which are distributed from Turkey through the Iranian Plateau to India as follows: south-eastern Turkey, Syria, Iraq, Iran, Pakistan, Afghanistan, Turkmenistan, and north-eastern and central India (Mirza et al. 2014) in a variety of habitats from dry karst topography regions with gypsum deposits and clay-gravel soil to stony foothills (Šmíd et al. 2014). In Iran, the leopard geckos comprise three species with a vicariant distribution: the Iranian fat-tailed gecko, E. angramainyu Anderson \& Leviton, 1966, which occurs west and southwest of the Zagros Mountains to southwest Kerman Province; E. macularius (Blyth, 1854), of which the only known locality is in the eastern region of South Khorasan Province (close to the AfghanistanIran border); and E. turcmenicus Darevsky, 1977 from the Turkmen borders in North Khorasan and Khorasan 
Razavi Provinces, north-eastern Iran (Auer et al. 2008; Šmíd et al. 2014).

In this study, we focus on E. angramainyu by using maximum entropy distribution modelling to (1) identify potential areas of distribution during the last interglacial (LIG: 150,000-120,000 years ago) and mid-Holocene (MH: 6,000 years ago) periods; (2) describe the contemporary $(\sim 1950-2000)$ distribution, suitable habitats, and understanding of biogeographical patterns; and (3) predict suitable distribution areas for the future (2050).

\section{MATERIALS AND METHODS}

Occurrence Data. The study area encompasses the territory of the nocturnal lizard, E. angramainyu (Figure 1) from southern Turkey, north-eastern Syria, and Iraq to southern and south-eastern regions of the Iranian Plateau (Anderson 1999; Karamiani and Rastegar-Pouyani 2010; Moradi and Shafiei 2011). The occurrence data of the Iranian specimens were gathered based on a systematic biological survey by walking randomly through the habitat from dusk ( 9:00 PM) to dawn ( 5:00 AM) (much of the activity time of the species) during several herpetofaunal studies from spring to summer 2010-2019. The exact coordinates were recorded using a Global Positioning System (Garmin
GPSmap 60CSx). The distribution data were collected in limestone and gypsum foothills and steppes of the Zagros Mountains from Bazideraz region and Sumar of Kermanshah, Pol-e Dokhtar of Lorestan, Dehloran and Darreh Shahr of Ilam, and Masjed-e-Suleiman and Ramhormoz of Khuzestan Provinces (Figure 2). In other areas (Kohgiluyeh and Boyer-Ahmad and Fars Provinces), E. angramainyu specimens were observed between the shrubs and steppes of the Zagros Mountains. The records mentioned in previous studies (e.g. Anderson and Leviton 1966; Leviton et al. 1992; Anderson 1999; Göçmen et al. 2002; Tosunoğlu et al. 2005; Üzüm et al. 2008; Karamiani and RastegarPouyani 2010; Torki 2010; Moradi and Shafiei, 2011; Šmíd et al. 2014) and localities from the Global Biodiversity Information Facility (GBIF: https://www.gbif. org) website (GBIF 2020) were also included. In total, 85 records were gathered and used in this study.

Environmental Data and Analysis. The maximum entropy modelling (MaxEnt, 3.3.3e http://www. cs.princeton.edu/ schapire/MaxEnt) approach was used for the analysis of species geographic distributions under default parameters. All variables were downloaded from the WorldClim website (http://www.worldclim.org) (Table S1). For the modelling of the past distribution (LIG and $\mathrm{MH}), 19$ bioclimatic variables were included at a spatial resolution of $10 \mathrm{~km}^{2}(5 \mathrm{~min} \times 5 \mathrm{~min})$. For

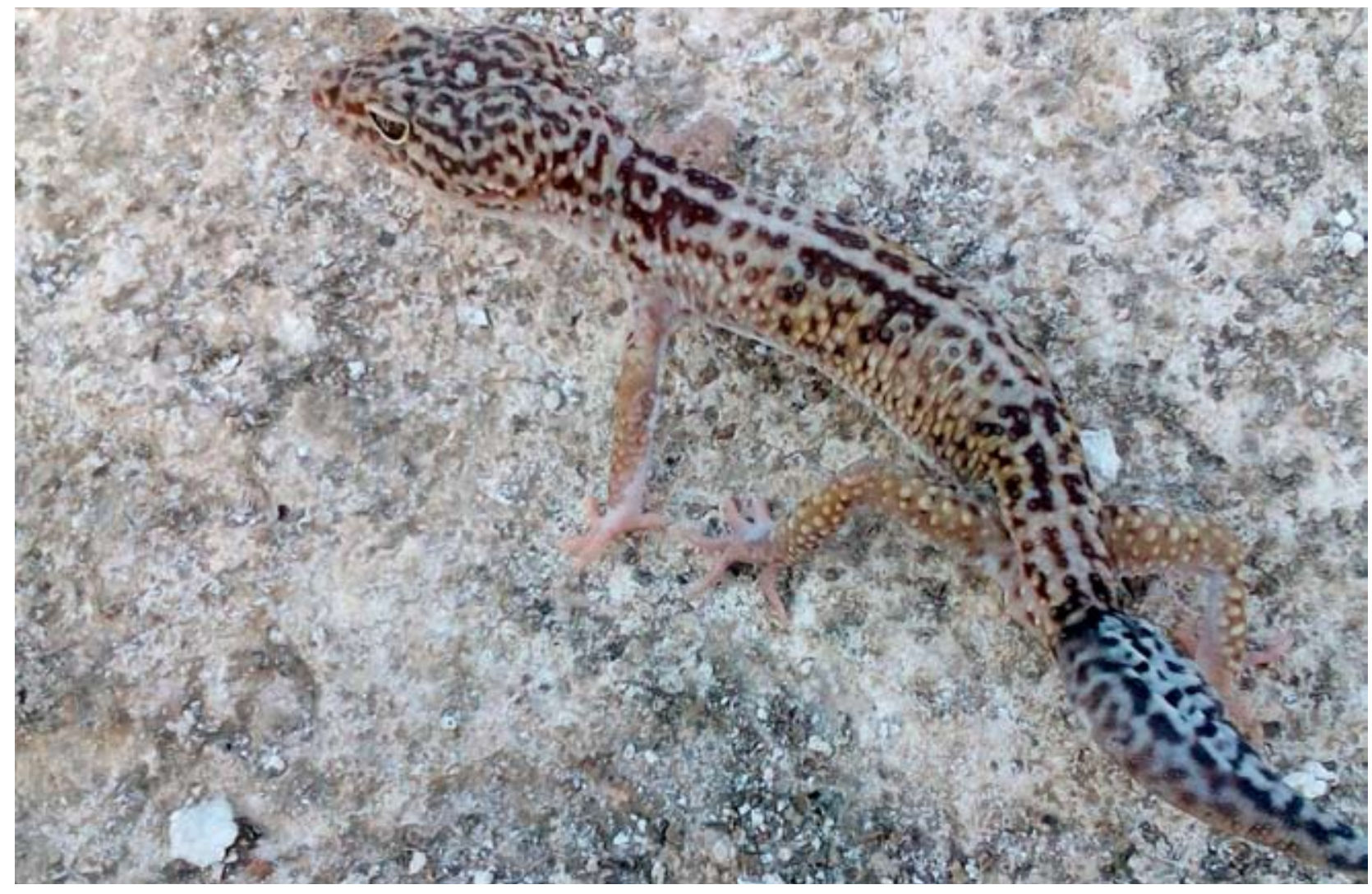

Figure 1. Alive adult specimen of Eublepharis angramainyu with a regenerated tail. 

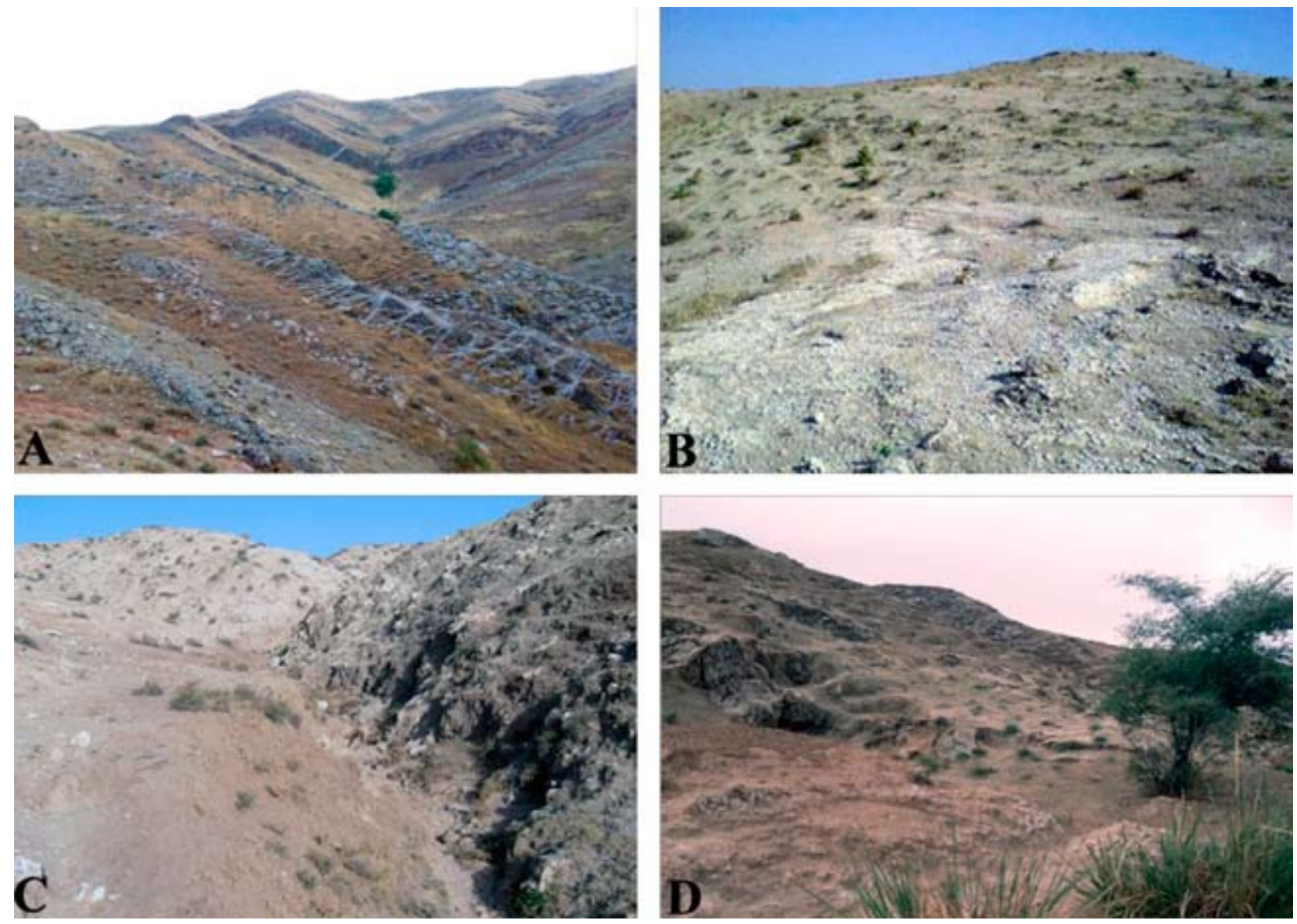

Figure 2. General aspect of habitat of Eublepharis angramainyu in Bazideraz Region, Kermanshah Province (A); Pol-e Dokhtar, Lorestan Province (B); Masjed-e-Suleiman (C), and Ramhormoz (D), Khuzestan Province.

the contemporary period (1950-2000), the same 19 bioclimatic variables and two topographical variables with a spatial resolution of $1 \mathrm{~km}^{2}(30 \mathrm{~s} \times 30 \mathrm{~s})$ were used. Finally, for modelling future (2050) distribution the 19 bioclimatic variables were used at a spatial resolution of $1 \mathrm{~km}^{2}(30 \mathrm{~s} \times 30 \mathrm{~s})$ and under four future climatic scenarios in the Middle East (southwest Asia).

The future scenarios are as follows: in the representative concentration pathway RCP 2.6 scenario, greenhouse gas concentration levels are very low under a peak-anddecline scenario; its radiative forcing level first reaches a value of around $3.1 \mathrm{~W} / \mathrm{m}^{2}$ by mid-century (2050) and returns to $2.6 \mathrm{~W} / \mathrm{m}^{2}$ by 2100 (Van Vuuren et al. 2007); in the RCP 4.5 scenario, the total radiative forcing is stabilized before 2100 by employment of a range of technologies and strategies for reducing greenhouse gas emissions (Wise et al. 2009); the RCP 6.0 scenario is a stabilization scenario where the total radiative forcing is stabilized after 2100 without overshoot by employment of a range of technologies and strategies for reducing greenhouse gas emissions (Fujino et al. 2006; Hijioka et al. 2008); and finally the RCP 8.5 scenario is a scenario of increasing greenhouse gas emissions over time, representative of scenarios in the literature that lead to high greenhouse gas concentration levels (Riahi et al. 2007). OpenModeller (V. 1.1.0) (de Souza Muñoz et al. 2011) was used to identify correlations between variables and presence records. We used the IBM SPPS (version 24) for Pearson's correlation coefficient (Elith et al. 2006) to select variables with a correlation lower than 0.75 (Karamiani et al. 2018). We used MaxEnt software with 15 replicates of analysis to obtain the best model for the Iranian fat-tailed gecko. The DIVA-GIS 7.5.0.0 software (available at http://www.diva-gis.org) was utilized for the mean predicted map and a logistic output of presence records with suitability ranging from zero (unsuitable habitat) to one (the best suitable habitat) (Hijmans et al. 2001). General aspect of habitat of Eublepharis angramainyu in Bazideraz Region, Kermanshah Province (A); Pol-e Dokhtar, Lorestan Province (B); Masjed-e-Suleiman (C), and Ramhormoz (D), Khuzestan Province.

\section{RESULTS}

The distribution of the Iranian fat-tailed gecko $E$. angramainyu was best described by a combination of 
Table 1. Relative importance of variables (in percentages) in the last interglacial (LIG, $\sim 120 \mathrm{ka}$ ), mid-Holocene (MH, $\sim 6 \mathrm{ka}$ ), and contemporary period (1950-2000) used in MaxEnt model for the Iranian fat-tailed gecko, E. angramainyu.

\begin{tabular}{|l|l|c|c|c|}
\hline Variable & \multicolumn{1}{|c|}{ Description of variables } & LIG & MH & $1950-2000$ \\
\hline Bio18 & Precipitation of the warmest quarter of the year & 52.6 & 49.2 & - \\
\hline Bio19 & Precipitation of the coldest quarter of the year & 26.3 & 32.3 & 41.5 \\
\hline Bio14 & Precipitation of the driest month & 13.8 & 16.3 & $=$ \\
\hline Bio2 & Annual daily temperature difference (minimal temperature -maximal temperature) & 2.7 & 0.6 & 1.7 \\
\hline Bio11 & Mean temperature of the coldest quarter of the year & 2.4 & 1.6 & 27.7 \\
\hline Bio3 & Isothermality [(BIO2 / BIO7) $\times 100]$ & 2.1 & - & 6.7 \\
\hline Bio15 & Seasonality of precipitation (coefficient of variation) & 0.1 & - & 8.4 \\
\hline Bio16 & Precipitation of wettest quarter & - & - & 3.5 \\
\hline Altitude & Altitude & - & - & 5.6 \\
\hline Slope & Slope & - & - & 4.8 \\
\hline
\end{tabular}

Table 2. Relative importance of variables (in percentages) in the future (2050) with RCP 2.6, RCP 4.5, RCP 6.0, and RCP 8.5 scenarios used in MaxEnt model for the Iranian fat-tailed gecko, E. angramainyu.

\begin{tabular}{|c|c|c|c|c|c|}
\hline Variable & Description of variables & RCP 2.6 & RCP 4.5 & RCP 6.0 & RCP 8.5 \\
\hline Bio18 & Precipitation of the warmest quarter of the year & 65.8 & 65.6 & 66.6 & 65.9 \\
\hline Bio19 & Precipitation of the coldest quarter of the year & 31.2 & 29.2 & 29.3 & 31.1 \\
\hline Bio9 & Mean temperature of the driest quarter of the year & - & 4.4 & 3.7 & - \\
\hline Bio2 & $\begin{array}{l}\text { Annual daily temperature difference (minimal temperature - } \\
\text { maximal temperature) }\end{array}$ & 1.2 & 0.5 & - & 0.9 \\
\hline
\end{tabular}

bioclimatic and geographic variables, that was suggested by a high value of the area under the curve (AUC) values $(\mathrm{LIG}=0.996 \pm 0.003, \mathrm{MH}=0.996 \pm 0.004$, contemporary period $=0.995 \pm 0.004$, and the future $=$ $0.997 \pm 0.002$ ). The models exhibited a very good match and closely fitted the presence of the species recorded in the study areas. The contribution of different variables to different time periods is shown in Table 1. In the LIG and MH models, precipitation of the warmest quarter of the year (163-170 $\mathrm{mm}$ ) explained near half of the variance (49-52.6\%); precipitation of the coldest quarter of the year $(113-116 \mathrm{~mm})$ and precipitation of the driest month $(28-31 \mathrm{~mm})$ explained $40-48.6 \%$ of the variance. Therefore, precipitation content was the most important factor for the simulated distribution models during the LIG and $\mathrm{MH}$ periods (Figure 3A and $\mathrm{B})$. In the contemporary model, precipitation and mean temperature of the coldest quarter justified $69 \%$ of the variance, where mean precipitation was $220 \mathrm{~mm}$ with temperature of $6-15^{\circ} \mathrm{C}$ (Figure 3C). In future models of the RCP 2.6, RCP 4.5, RCP 6.0, and RCP 8.5 , summation variables of precipitation of the warmest quarter of the year (Bio18) and precipitation of the coldest quarter of the year (Bio19) explained 97\%, $94.8 \%, 95.9 \%$, and $97 \%$ of the variance, respectively (Table 2), as E. angramainyu only occurred in areas where mean precipitation was 134-175 mm (Figures 4 and 5). The model for E. angramainyu predicted the occurrence range of the species in gypsum deposits and mountainsides with elevation of 27 to $2099 \mathrm{~m}$ above sea level (a.s.1.) and slopes to $89^{\circ}$.

\section{DISCUSSION}

Results of the present study verify the known distribution of the Iranian fat-tailed gecko based on climatic conditions. The western and south-western regions of the Iranian Plateau, north-eastern Iraq, and southern Turkey to the Levant had a wide variety of area suitability for the presence of E. angramainyu during four time periods: $\mathrm{LIG}, \mathrm{MH}$, contemporary, and future. The only exception is a record (one male specimen) from the southwest of Kerman Province, south-eastern Iran by Moradi and Shafiei (2011) in rocky desert and arid grasslands habitat.

In western and south-western regions of the Iranian Plateau, E. angramainyu occurs in karst features (cavities, subsidence areas and sinkholes) as well as in gypsum hills (e.g. Qasr-e Shirin and Sarpol-e Zahab in Kermanshah Province; Dehloran, and Dare Shahr in Ilam Province; Pol-e Dokhtar in Lorestan Province; Masjed-e-Suleiman and Ramhormoz in Khuzestan Province; Nourabad Mamasani in Fars Province (Šmíd et al. 2014)). In conformity with the results, Boulenger (1885) recorded a specimen from the ruins of Nineveh, in the upper Mesopotamian Plain (Leviton et al. 1992), and also Anderson (1999) mentioned two localities (a specimen from near the village of Chalga, south of Chem-che, Kirkuk Province, and another from Khanaqain area, Diyala Province) in Iraq. The species is also recorded from Al-Khatonia in Al-Hasakah Province, north-eastern Syria (Martens and Kock 1991). 
Also, the Iranian fat-tailed gecko occurs on the ground enriched by clay-limestone in southern Turkey (Göçmen et al. 2002). The results showed that the distribution of the species is restricted by different climatic factors. Model distribution ranges during the $\mathrm{MH}$ to
1950-2000 indicated a gradual decline of habitat suitability in Cyprus and the Levant to Iran. During summer, the rainfall fluctuations over the regions show a clear decrease from the $\mathrm{MH}$ to contemporary time that can be elucidated by the changes in solar insolation due to
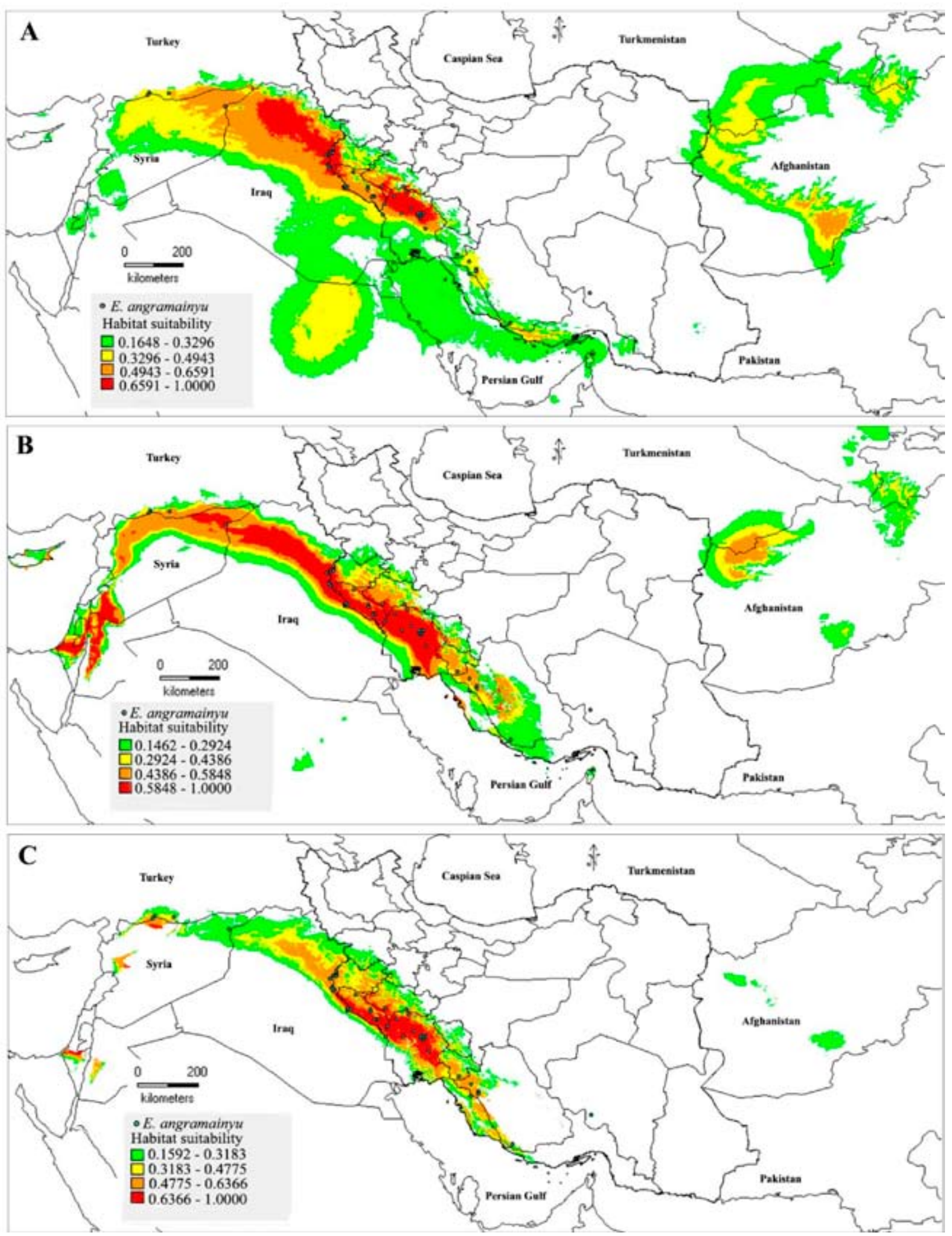

Figure 3. Distribution map of Eublepharis angramainyu and its potential distribution pattern during: A) the last interglacial ( $\sim 120 \mathrm{ka}), \mathrm{B})$ the mid-Holocene ( $\sim 6 \mathrm{ka})$, and C) contemporary period (1950-2000). 
the varying orbital forcing (Fallah et al. 2017). Model distribution ranges of 2050 with each scenario (RCP: $2.6,4.5,6.0,8.5)$ predicated more habitat suitability than before, probably due to precipitation during the Sudan monsoon. The LIG and MH distribution models were influenced by precipitation of the warmest quarter $(52.6 \% ; 49.2 \%)$, precipitation of the coldest quarter $(26.3 \% ; 32.3 \%)$, and the driest month $(13.8 \% ; 16.3 \%)$. As it seems based on the results, due to the relationship between precipitation and influx water in karsts and cavities of gypsum deposit, we think that precipitation, especially during summer, is the most effective factor determining the habitat suitability for E. angramainyu. In addition to habitat change, decreasing connectivity between suitable habitats and consequent reduction of gene flow among populations leads to an increased extinction risk (Fischer and Lindenmayer 2007; Ferraz et al. 2007). Although there was a relatively good habitat connectivity within landscapes in the past and contemporary climatic models, an overall decrease is expected across E. angramainyu distribution range due to climate change. Four patterns are predicted due to climate changes in our modelling. First, a suitable habitat is expected to almost disappear in the areas of climate change, such as in Ilam Province. Second, the size of suitable habitats in large cities will decrease, such as in Khuzestan Province. Third, some increases in suitable habitats are predicted in Iran (Bohsher, Fars, Kohgiluyeh and Boyer-Ahmad, Chaharmahal and Bakhtiari, Lorestan, and Kermanshah Provinces) as well as in Iraq (Diyala, Salah al-Din, Kirkuk, Nineveh Provinces) (Figure 5). Therefore, depending on the region, climatic changes can cause disappearance/ decrease as well as partial expansion of suitable habitats (Parmesan 2006; Bonino et al. 2015; Kim et al. 2020). These latter regions might function as potential refuges for conservation of the species under changing climate in the future (Kim et al. 2020).

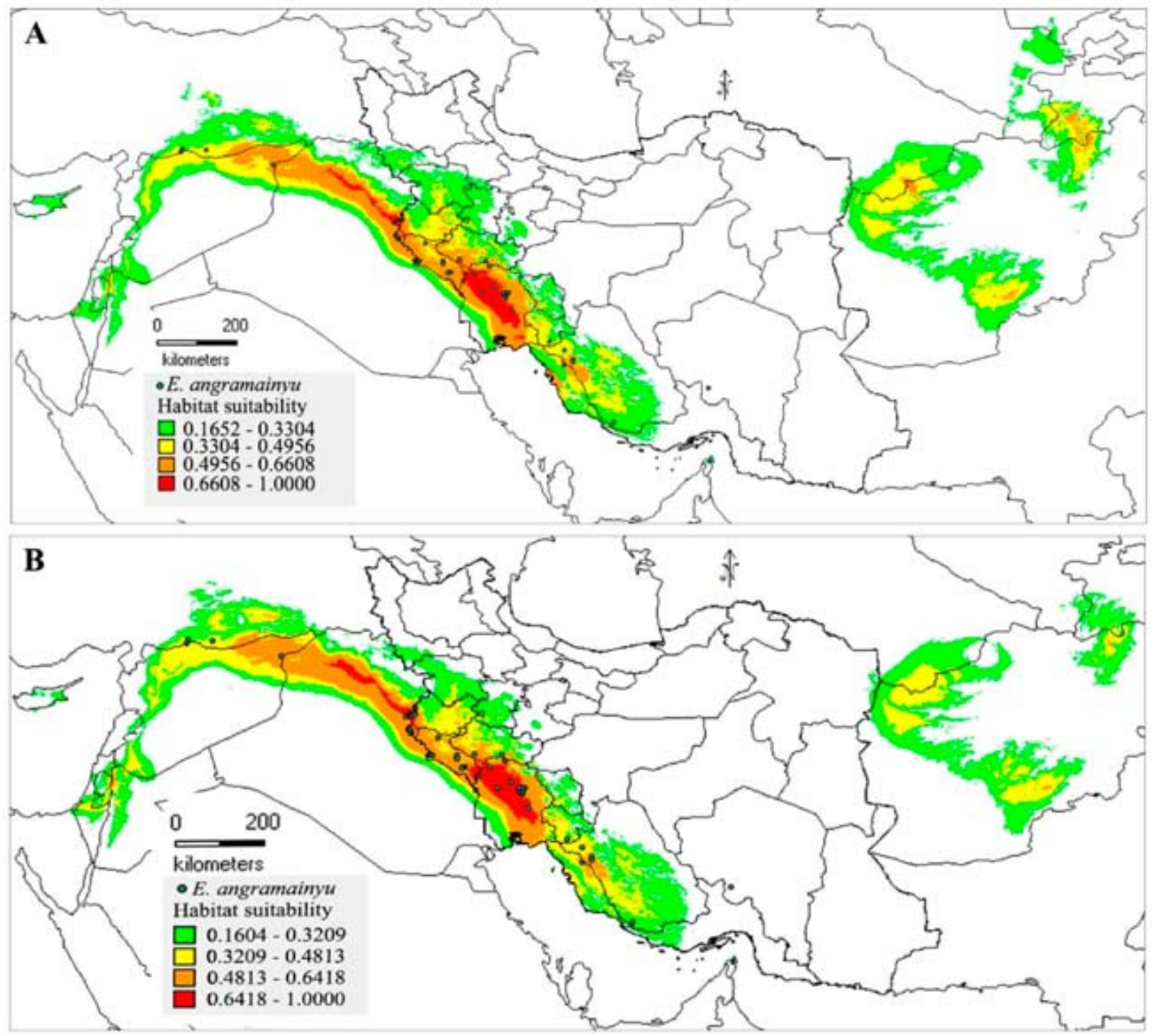

Figure 4. Predicted distribution of Eublepharis angramainyu during 2050: A) scenario RCP 2.6, B) scenario RCP 4.5. 

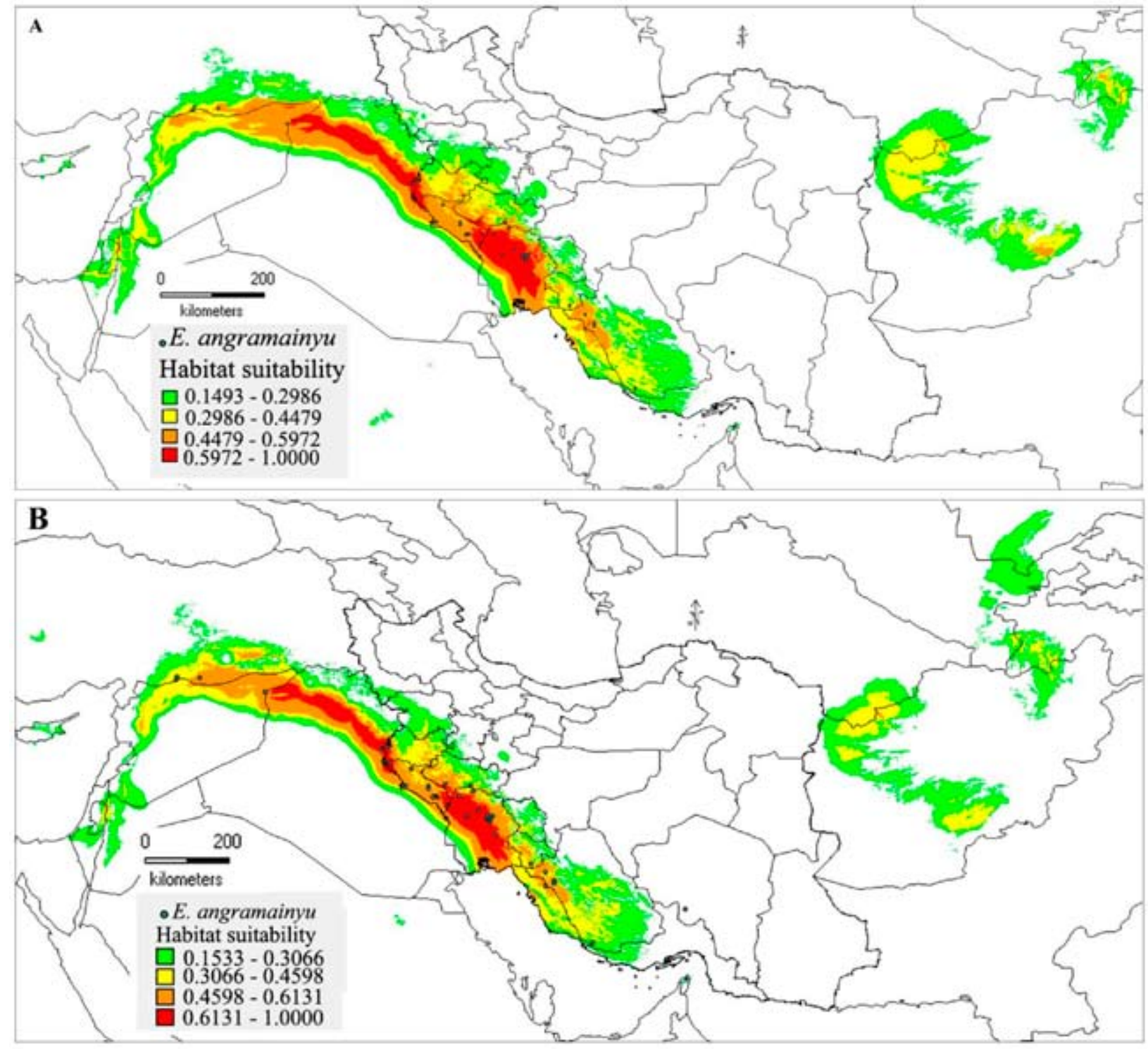

Figure 5. Predicted distribution of Eublepharis angramainyu during 2050: A) scenario RCP 6.0, B) scenario RCP 8.5.

\section{ACKNOWLEDGMENTS}

We wish to thank Ali Bazdar, Ali Permanoon, Erfan Permanoon, Akbar Fattahi, and Morad Besharati for assisting us with field work. Also, we would like to thank the anonymous reviewers for their comments and suggestions to improve the paper. We are grateful to the authorities of Razi University (Kermanshah, Iran) for financial support during the field work.

\section{REFERENCES}

Anderson, S. C. 1999. The lizards of Iran. Oxford, Ohio: Society for the Study of Amphibians and Reptiles, $442 \mathrm{pp}$.

Anderson, S. C., and A. E. Leviton.1966. A new species of Eublepharis from southwestern Iran (Reptilia: Gekko- nidae). Occasional Papers of the California Academy of Sciences 53: 1-5.

Auer, M., S. Richter, and A. Khani. 2008. A new record of the Turkmenian fat-tailed gecko, Eublepharis turcmenicus Darevsky, 1978, from north-eastern Iran (Squamata: Gekkonidae). Zoology in the Middle East 45 (1): 107-110.

Bonino, M. F., D. L. M. Azócar, J. A. Schulte, and F. B. Cruz. 2015. Climate change and lizards: changing species' geographic ranges in Patagonia. Regional Environmental Change 15 (6): 1121-1132.

Boulenger, G. A. 1885. Catalogue of the lizards in the British Museum (Natural History) Geckonidae, Eublepharidae, Uroplatidae, Pygopodidae, Agamidae, (Vol. 1). London: Trustees of the British Museum, xii +497 pp. de Souza Muñoz, M. E., R. De Giovanni, M. F. de Siqueira, T. Sutton, P. Brewer, R. S. Pereira, D. A. L. Canhos, and V. P. Canhos. 2011. Openmodeller: A generic approach 
to species' potential distribution modelling. GeoInformatica 15 (1): 111-135.

Elith, J., C. H. Graham, R. P. Anderson, M. Dudík, S. Ferrier, A. Guisan, R. J. Hijmans, F. Huettmann, J. R. Leathwick, A. Lehmann, J. Li, L. G. Lohmann, B. A. Loiselle, G. Manion, C. Moritz, M. Nakamura, Y. Nakazawa, J. M. Overton, A. T. Peterson, S. J. Phillips, K. S. Richardson, R. Scachetti- Pereira, R. E.Schapire, J. Soberon, S. Williams, M. S. Wisz, N. E. Zimmermann. 2006. Novel methods improve prediction of species' distributions from occurrence data. Ecography 29 (2): 129-151.

Fallah, B., S. Sodoudi, E. Russo, I. Kirchner, and U. Cubasch. 2017. Towards modelling the regional rainfall changes over Iran due to the climate forcing of the past 6000 years. Quaternary International 429: 119-128.

Ferraz, G., J. D. Nichols, J. E. Hines, P. C. Stouffer, R. O. Bierregaard, and T. E. Lovejoy. 2007. A large-scale deforestation experiment: effects of patch area and isolation on Amazon birds. Science 315 (5809): 238-241.

Fischer, J., and D. B. Lindenmayer. 2007. Landscape modification and habitat fragmentation: a synthesis. Global ecology and biogeography 16 (3): 265-280.

Fujino, J., R. Nair, M. Kainuma, T. Masui, and Y. Matsuoka. 2006. Multi-gas mitigation analysis on stabilization scenarios using AIM global model. The Energy Journal (Special Issue \# 3).

Göçmen, B., M. Tosunoğlu, and D. Ayaz. 2002. First record of the leopard gecko Eublepharis angramainyu (Reptilia: Sauria: Eublepharidae) from Anatolia. Herpetological Journal 12 (2): 79-80.

Gogol-Prokurat, M. 2011. Predicting habitat suitability for rare plants at local spatial scales using a species distribution model. Ecological Applications 21 (1): 33-47.

Hellmann, J. J., J. E. Byers, B. G. Bierwagen, and J. S. Dukes. 2008. Five potential consequences of climate change for invasive species. Conservation biology 22 (3): 534-543.

Hijioka, Y., Y.Matsuoka, H. Nishimoto, M. Masui, and M. Kainuma. 2008. Global GHG emissions scenarios under GHG concentration stabilization targets. Journal of Global Environmental Engineering 13: 97-108.

Hijmans, R., M. Cruz, E. Rojas, and L. Guarino. 2001. DIVAGIS, version 1.4. A geographic information system for the management and analysis of genetic resources data. Plant Genetic Resources Newsletter 15-19. http:// www.gbif.org. Occurrence Download https://doi. org/10.15468/d1.ywygqv [Accessed: 08 March 2020]

Jones, M., M. Djamali, L. Stevens, V. Heyvaert, H. Askari, D. Norolahie, and L. Weeks. 2011. Mid Holocene environmental and climatic change in Iran. In Ancient Iran and its Neighbours, Local Developments and Longrange Interactions in the 4th Millenium $B C$, edited by Petrie C. Oxford, UK: British Institute for Persian Studies and Oxbow Books.
Karamiani, R., and N. Rastegar-Pouyani. 2010. New specimens of Eublepharis angramainyu Anderson \& Leviton, 1966 (Sauria: Eublepharidae), from southwestern regions of the Iranian Plateau. Hamadryad 35: $116-121$.

Karamiani, R., N. Rastegar-Pouyani, and E. Rastegar-Pouyani. 2018. Modeling the Past and Current Distribution and Habitat Suitability for Ablepharus grayanus and A. pannonicus (Sauria: Scincidae). Asian Herpetological Research 9 (1): 56-64.

Kim, D. I., I. K. Park, S.Y. Bae, J. J. Fong, Y. P. Zhang, S. R. Li, H. Ota, J. S. Kim, and D. Park. 2020. Prediction of present and future distribution of the Schlegel's Japanese gecko (Gekko japonicus) using MaxEnt modeling. Journal of Ecology and Environment 44 (1): 1-8.

Kukla, G. J., M. L. Bender, J. L. de Beaulieu, G. Bond, W. S. Broecker, P. Cleveringa, J. E. Gavin, T. D. Herbert, J. Imbrie, J. Jouzel, and L. D. Keigwin. 2002. Last interglacial climates. USGS Staff-Published Research, $174 \mathrm{pp}$.

Leviton, A. E., S. C. Anderson, K. K. Adler, and S. A. Minton. 1992. Handbook to Middle East Amphibians and Reptiles. Contributions in Herpetology. No. 8. Oxford $(\mathrm{OH})$ : Society for the Study of Amphibians and Reptiles.

López-Alcaide, S., and R. Macip-Ríos. 2011. Effects of climate change in amphibians and reptiles. Biodiversity loss in a changing planet: 163-184.

Martens, H., and D. Kock. 1991. Erstnachweise für drei Gecko-Gattungen in Syrien (Reptilia: Sauria: Gekkonidae). Senckenbergiana biologica 71 (1-3): 15-21.

Mirza, Z. A., R. V. Sanap, D. Raju, A. Gawai, and P. Ghadekar. 2014. A new species of lizard of the genus Eublepharis (Squamata: Eublepharidae) from India. Phyllomedusa: Journal of Herpetology 13 (2): 75-90.

Moradi, N., and S. Shafiei. 2011. New record of the Western leopard gecko, Eublepharis angramainyu Anderson and Leviton, 1966 (Squamata: Eublepharidae) from southeastern Iran. Amphibian and Reptile Conservation (5): 88-91.

Parmesan, C. 2006. Ecological and evolutionary responses to recent climate change. Annual Reviews of Ecology, Evolution and Systematics 37: 637-669.

Pickarski, N. 2014. Vegetation and climate history during the last glacial-interglacial cycle at Lake Van, eastern Anatolia. PhD Thesis. Universitäts-und Landesbibliothek Bonn.

Ray, L. L. 1992. The Great Ice Age. US Department of the Interior, US Geological Survey.

Riahi, K., A. Grübler, and N. Nakicenovic. 2007. Scenarios of long-term socio-economic and environmental development under climate stabilization. Technological Forecasting and Social Change 74 (7): 887-935.

Sillero, N., and M. A. Carretero. 2013. Modelling the past 
and future distribution of contracting species. The Iberian lizard Podarcis carbonelli (Squamata: Lacertidae) as a case study. Zoologischer Anzeiger-A Journal of Comparative Zoology 252 (3): 289-298.

Šmíd, J., J. Moravec, P. Kodym, L. Kratochvíl, S. S. H. Yousefkhani, E. Rastegar-Pouyani, and D. Frynta. 2014. Annotated checklist and distribution of the lizards of Iran. Zootaxa 3855 (1): 1-97.

Texier, D., N. De Noblet, and P. Braconnot. 2000. Sensitivity of the African and Asian monsoons to mid-Holocene insolation and data-inferred surface changes. Journal of Climate 13 (1): 164-181.

Thomas, C. D., A. Cameron, R. E. Green, M. Bakkenes, L. J. Beaumont, Y. C. Collingham, B. F. Erasmus, M. F. De Siqueira, A. Grainger, L. Hannah, and L. Hughes. 2004. Extinction risk from climate change. Nature 427 (6970): 145-148.

Torki, F. 2010. Distribution, lifestyle, and behavioral aspects of the Iranian fat-tailed gecko, Eublepharis angramainyu Anderson and Leviton, 1966. Gekko 6 (1): 17-22.

Tosunoğlu, M., D. Ayaz, C. V. Tok, K. Olgun, and M. Afşar. 2005. Morphology of Eublepharis angramainyu Anderson and Leviton, 1966 in Turkey. Herpetozoa 18 (1/2): 61-62.

Üzüm, N., A. Avcı, Ç. Ilgaz, and K. Olgun. 2008. A new specimen of Eublepharis angramainyu Anderson and Leviton, 1966 (Reptilia: Sauria: Eublepharidae), Leopard gecko, in south eastern Anatolia, Turkey. Russian Journal of Herpetology 15 (2): 129-132.

Van Vuuren, D. P., M. G. Den Elzen, P. L. Lucas, B. Eickhout, B. J. Strengers, B. Van Ruijven, S. Wonink, and R. Van Houdt. 2007. Stabilizing greenhouse gas concentrations at low levels: an assessment of reduction strategies and costs. Climatic change 81 (2): 119-159.

Visser, M. E. 2008. Keeping up with a warming world; assessing the rate of adaptation to climate change. Proceedings of the Royal Society B: Biological Sciences 275 (1635): 649-659.

Walther, G. R., E. Post, P. Convey, A. Menzel, C. Parmesan, T. J. Beebee, J. M. Fromentin, O. Hoegh-Guldberg, and F. Bairlein. 2002. Ecological responses to recent climate change. Nature 416 (6879): 389-395.

Wanner, H., J. Beer, J. Bütikofer, T. J. Crowley, U. Cubasch, J. Flückiger, H. Goosse, M. Grosjean, F. Joos, J. O. Kaplan, and M. Küttel. 2008. Mid-to Late Holocene climate change: an overview. Quaternary Science Reviews 27 (19-20): 1791-1828.

Wise, M., K. Calvin, A. Thomson, L. Clarke, B. Bond-Lamberty, R. Sands, S. J. Smith, A. Janetos, and J. Edmonds. 2009. Implications of limiting CO2 concentrations for land use and energy. Science 324 (5931): 1183-1186.

\section{SUPPLEMENTARY MATERIAL}

Table S1. Climatic and landscape variables used to elaborate the models (www.worldclim.org).

\begin{tabular}{|l|l|}
\hline Characters & Definition \\
\hline Altitude & Altitude \\
\hline BIO1 & Annual mean temperature \\
\hline BIO2 & Mean diurnal range [mean of monthly (max temp - min temp)] \\
\hline BIO3 & Isothermality [(BIO2 / BIO7) $* 100]$ \\
\hline BIO4 & Temperature seasonality (standard deviation * 100) \\
\hline BIO5 & Maximum temperature of the warmest month \\
\hline BIO6 & Minimum temperature of the coldest month \\
\hline BIO7 & Temperature annual range (BIO5 - BIO6) \\
\hline BIO8 & Mean temperature of the wettest quarter of the year \\
\hline BIO9 & Mean temperature of the driest quarter of the year \\
\hline BIO10 & Mean temperature of the warmest quarter of the year \\
\hline BIO11 & Mean temperature of the coldest quarter of the year \\
\hline BIO12 & Annual precipitation \\
\hline BIO13 & Precipitation of the wettest month \\
\hline BIO14 & Precipitation of the driest month \\
\hline BIO15 & Precipitation seasonality (standard deviation / mean) \\
\hline BIO16 & Precipitation of the wettest quarter of the year \\
\hline BIO17 & Precipitation of the driest quarter of the year \\
\hline BIO18 & Precipitation of the warmest quarter of the year \\
\hline BIO19 & Precipitation of the coldest quarter of the year \\
\hline Slope & Slope \\
\hline
\end{tabular}

